\title{
GCU
}

Glasgow Caledonian

University

University for the Common Good

\section{A robust and reliable optical trace oxygen sensor}

McDowell, G.R.; Holmes-Smith, A.S.; Uttamlal, M.; Mitchell, C.; Shannon, P.H.

Published in:

Optical Sensors 2017

DOI:

$10.1117 / 12.2265561$

Publication date:

2017

Document Version

Author accepted manuscript

Link to publication in ResearchOnline

Citation for published version (Harvard):

McDowell, GR, Holmes-Smith, AS, Uttamlal, M, Mitchell, C \& Shannon, PH 2017, A robust and reliable optical trace oxygen sensor. in F Baldini, J Homola \& RA Lieberman (eds), Optical Sensors 2017. vol. 10231, 102310T, SPIE, SPIE Optics and Optoelectronics 2017, Prague, Czech Republic, 24/04/17.

https://doi.org/10.1117/12.2265561

\section{General rights}

Copyright and moral rights for the publications made accessible in the public portal are retained by the authors and/or other copyright owners and it is a condition of accessing publications that users recognise and abide by the legal requirements associated with these rights.

Take down policy

If you believe that this document breaches copyright please view our takedown policy at https://edshare.gcu.ac.uk/id/eprint/5179 for details of how to contact us. 


\title{
A robust and reliable optical trace oxygen sensor
}

\author{
G. R. McDowell*a , A. S. Holmes-Smith ${ }^{\mathrm{a}}$, M. Uttamlal ${ }^{\mathrm{a}}$, C. Mitchell ${ }^{\mathrm{b}}$, P. H. Shannon ${ }^{\mathrm{b}}$ \\ ${ }^{a}$ School of Engineering and Built Environment, Glasgow Caledonian University, Cowcaddens Road, \\ G4 0BA, Glasgow, Scotland, UK

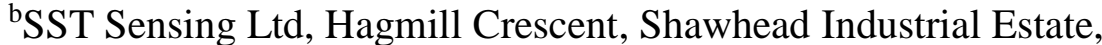 \\ ML5 4NS, Coatbridge, Scotland, UK
}

\begin{abstract}
In applications of nitrogen $\left(\mathrm{N}_{2}\right)$ generation, industrial gas manufacturing and food packaging there is a need to ensure oxygen $\left(\mathrm{O}_{2}\right)$ is absent from the environment, even at the lowest concentration levels. Therefore, there has been an increased growth in the development of trace $\mathrm{O}_{2}$ parts per million (ppm) sensors over the past decade to detect and quantify the concentration of molecular $\mathrm{O}_{2}$ in the environment whether it be dissolved or gaseous $\mathrm{O}_{2}$. The majority of commercially available trace $\mathrm{O}_{2}$ sensors are based on electrochemical, zirconia and paramagnetic technologies. Here, the development of a luminescence-based optical trace $\mathrm{O}_{2}$ sensor is presented. Luminescence-based sensing is now regarded as one of the best techniques for the detection and quantification of $\mathrm{O}_{2}$. This is due to the high detection sensitivity, no $\mathrm{O}_{2}$ is consumed and there are a vast array of luminescent indicators and sensing platforms (polymers) that can be selected to suit the desired application. The sensor will be shown to operate from $-30{ }^{\circ} \mathrm{C}$ to $+60{ }^{\circ} \mathrm{C}$ in the $0-1000 \mathrm{ppm}$ and/or $0-1200 \mu$ bar partial pressure of oxygen $\left(\mathrm{ppO}_{2}\right)$ range and is equipped with temperature and pressure compensation. The luminescence non-depleting principle, sensor specifications and miniaturized nature offers an attractive alternative to other sensing technologies and advantages over other luminescence-based $\mathrm{O}_{2}$ ppm sensors.
\end{abstract}

Keywords: Luminescence, optical sensor, trace oxygen.

\section{INTRODUCTION}

\subsection{Background}

$\mathrm{O}_{2}$ is one of the most important chemical species and is vital for the survival of most living organisms. ${ }^{1}$ However, in applications such as nitrogen $\left(\mathrm{N}_{2}\right)$ generation, industrial gas manufacturing and food packaging there is a need to ensure $\mathrm{O}_{2}$ is absent, even at the lowest concentration levels. Therefore, trace $\mathrm{O}_{2}$ parts per million (ppm) sensors have been developed with the most common technologies being that of electrochemical, zirconia and paramagnetic methods.

Electrochemical sensors are the most widely used as they are low cost, small, accurate and have a reasonable operational lifetime. However, they suffer from long recovery times and deplete when exposed to ambient $\mathrm{O}_{2}$ (air) thus calibration and/or replacement is required periodically. Zirconia and Paramagnetic sensors offer longer operational lifetimes however, they are expensive and Zirconia sensors require a high temperature for operation. The conventional method is the Clark Electrode ${ }^{2}$ but $\mathrm{O}_{2}$ is consumed, the electrode is prone to electrical interferences and has a limited operational lifetime. Clark-type microelectrodes have been developed but they are expensive to fabricate, fragile and their usefulness is limited. ${ }^{3}$ For applications where these considerations are important, optical methods, in particular, luminescence-based trace $\mathrm{O}_{2}$ sensors have been developed.

It is well known that $\mathrm{O}_{2}$ is an efficient quencher of luminescence. ${ }^{4}$ Luminescence-based sensing is now regarded as one of the best techniques for $\mathrm{O}_{2}$ sensing ${ }^{5}$ due to high detection sensitivity, no analyte consumption and there are a vast array of luminescent indicators and sensing platforms that can be selected to suit the desired application. ${ }^{6}$ The luminescence emission intensity and/or excited state lifetime (decay time) of a luminescent indicator is related to $\mathrm{O}_{2}$ concentration through the Stern-Volmer equation: 


$$
\frac{I_{o}}{I}=\frac{\tau_{o}}{\tau}=1+\left(K_{S V} p p O_{2}\right)=1+\left(k_{q} \tau_{o} p p O_{2}\right)
$$

where $I_{0}, I, \tau_{0}$ and $\tau$ are the luminescence intensity and decay time in the absence and presence of the quencher respectively. $k_{q}$ is the biomolecular quenching constant, $\mathrm{ppO}_{2}$ is the partial pressure of oxygen and $K_{S V}$ is the SternVolmer quenching constant. Plots of $I_{0} / I$ and $\tau_{0} / \tau$ versus $\mathrm{O}_{2}$ concentration should yield a straight line. In many cases the line deviates from linearity which indicates that the luminophore exists in more than one environment and/or dynamic and static quenching are occurring concurrently. In these cases, nonlinear forms of the Stern-Volmer equation have been proposed..$^{7,8}$

SST currently market a luminescence-based $\mathrm{O}_{2}$ sensor (LuminOx) which measures $\mathrm{O}_{2}$ in the $0-25 \%$ range or $0-300$ $\mathrm{mBar} \mathrm{ppO}_{2}$ and can measure $\mathrm{O}_{2}$ in environments where the temperature range is $-30{ }^{\circ} \mathrm{C}$ to $+60{ }^{\circ} \mathrm{C}$. This is achieved through an extensive calibration process. Here, a new development of the LuminOx sensor for trace $\mathrm{O}_{2}$ measurement is described. The aim is to manufacture a low cost, small and robust gaseous oxygen sensor for this market place which is capable of operating for more than 5 years. The luminescent indicator within a proprietary polymer formulation will be changed from a ruthenium complex to a metalloporphyrin complex to ensure good sensitivity to low concentrations of $\mathrm{O}_{2}$. Also, the sensor will be developed to have a working temperature range of -30 to $+60{ }^{\circ} \mathrm{C}$ which is an improvement on other commercially available luminescence-based trace $\mathrm{O}_{2}$ sensors which tend to operate from -5 to $+50{ }^{\circ} \mathrm{C}$.

\subsection{Sensor considerations}

\subsubsection{Cross-sensitivity to temperature and pressure}

Besides choosing the correct luminescent indicator and sensing platform to suit the application for an optical sensor there are a few very important and fundamental parameters that must be considered. Although not a chemical parameter itself, it can be argued that virtually all sensors are cross-sensitive to temperature. ${ }^{1}$ This is especially the case for luminescencebased sensors as the excited state lifetime of a luminophore is dependent on the radiative $\left(k_{r}\right)$ and non-radiative $\left(k_{n r}\right)$ decay rates hence $K_{S V}$ is related to $\tau_{0}$ (Equation 1) and the diffusion coefficient, $D$, according to Equation 2:

$$
k_{q}=4 \pi g R^{*} N_{A} D
$$

where $g$ is the spin statistical factor, $R^{*}$ is the collision radius and $N_{A}$ is Avogadro's number. ${ }^{1}$ The dynamic quenching mechanism is a diffusion-dependent process and is therefore affected by temperature. During the development of a luminescence-based sensor it is therefore paramount that temperature must be compensated for, which will be shown here. In addition, a luminescent indicator can be selected that is less prone to thermal quenching i.e. $\mathrm{Pt}(\mathrm{II})$ metalloporphyrins tend to show less cross-sensitivity to temperature than $\mathrm{Ru}(\mathrm{II})$ polypyridyl complexes. ${ }^{9}$ In fact, the $\mathrm{Ru}$ (II) polypyridyl complex $\mathrm{Ru}(\mathrm{phen})_{3}$ is so sensitive to temperature it has been immobilized within a gas blocking polymer and used as a temperature sensor. ${ }^{10,11}$

Besides the oxygen-sensitive material the cross-sensitivity to temperature is dominated by the temperature dependence of the diffusion and solubility of $\mathrm{O}_{2}$ in polymers. Within the literature, remarkably, there is little work published highlighting the complexity of the relationship between temperature and the solubility of $\mathrm{O}_{2}$ in polymers. Another approach is to choose a polymer that shows less thermal dependence such as poly(hexafluoroisopropyl methacrylate)-co(heptafluoro-n-butyl methacrylate), FIB, a fluoropolymer for producing pressure-sensitive paints (PSPs) which has been used for wind-tunnel applications. ${ }^{12,13}$ In other work, dual sensing has become popular and are summarized by Wang and Wolfbeis. ${ }^{1}$ In this approach, two luminescent indicators are generally immobilised within one polymer support with one indicator being sensitive to temperature and the other $\mathrm{O}_{2}$. In some instances there have been reports of tri- and quadrupole sensors. ${ }^{14-17}$

An important parameter sometimes ignored is pressure. If the barometric pressure of an environment changes then the amount of $\mathrm{O}_{2}$ within the atmosphere also changes hence $\mathrm{ppO}_{2}$ is a more representative approach to take rather than $\mathrm{O}_{2}$ concentration (\%). Therefore, during the calibration process of an $\mathrm{O}_{2}$ sensor it is paramount to monitor and correct for changes in pressure as well as temperature. Once calibrated the $\mathrm{ppO}_{2}$ can then be converted to $\mathrm{O}_{2}$ as a percentage if required. 


\subsubsection{Photo- and long-term stability}

It is now generally regarded that the photobleaching or photodegradation of a luminescent indicator is caused by the formation of singlet $\mathrm{O}_{2}\left({ }^{1} \mathrm{O}_{2}\right)$ that is produced from the $\mathrm{O}_{2}$ quenching process. ${ }^{8}{ }^{818}$ Singlet $\mathrm{O}_{2}$ is a reactive species and can react with indicators to produce non-luminescent products and can attack polymer backbones thus causing oxidation of the oxygen sensitive layer. In addition a few factors can contribute to photobleaching or photodecomposition of the sensing layer, factors such as: (1) UV irradiation, (2) output power from an excitation source and (3) the sensitivity (reactivity) of the sensor to $\mathrm{O}_{2}$. The photostability of a luminescent indicator is not so critical when disposable sensors are used but is fundamental when high light intensity sources are required or prolonged measurements are needed thus the photostability can be related to the long-term stability due to steady-state drift of the sensor with time.

To minimize photobleaching of an indicator pulsed light excitation can be employed or sources with low radiant power. It has been reported that substituting the functional groups of indicators inhibits the oxidation leading to so called "photostabilizers". ${ }^{19}$ It has also been suggested that the Pt(II) and Pd(II) metalloporphyrins with fluorophenyl groups, such as Platinum (II) 5,10,15,20-Tetrakis(2,3,4,5,6-pentafluorophenyl)-porphyrin (PtTFPP) and the Pd(II) analogue are the most photostable indicators used besides $\mathrm{Ru}(\mathrm{dpp})_{3} .{ }^{5}$ The fluorophenyl group is large and rigid to oxidative attack and the electron-withdrawing character of the perfluorophenyl substituents strongly raises the redox potentials and the electron density of the complex thus PtTFPP and PdTFPP molecules are less reactive to photo-oxidation increasing photostability. ${ }^{20}$ In this work, PtTFPP is chosen for these reasons and is extremely sensitive to $\mathrm{O}_{2}$ hence providing the desired working range.

Within the literature, the majority of work investigating photostability tend to show sensor stability over a short period of time (a few hours). The limited reports that do investigate longer periods ( $>1$ year) measure the stability of the sensor intermitidly upon storing in ambient conditions or are based on luminescence intensity measurements. Nowadays, most luminescence-based $\mathrm{O}_{2}$ sensors are based on the luminescence lifetime principle using either time-domain or frequencydomain techniques as the luminescence lifetime of a luminophore is independent of the output power of an excitation source and luminophore concentration which would lead to erroneous results using a luminescence intensity based system. The sensor proposed here uses the time-domain principle.

For commercial considerations where long-term stability is required it is paramount to monitor the stability of the sensor under continuous operation and within a wide operating temperature range over a prolonged period of time.

\section{METHODOLOGY}

\subsection{Oxygen-sensitive layer}

All chemicals, reagents and polymers were purchased from commercial suppliers and were used as received. The luminescent dye used is the metalloporphyrin complex Platinum (II) 5,10,15,20-Tetrakis(2,3,4,5,6-pentafluorophenyl)porphyrin (PtTFPP). A $1 \mathrm{mM}$ PtTFPP solution was prepared using dichloromethane (DCM) solvent. This was added to a known quantity of a glass matrix to immobilise the luminescent dye. The glass was then coated with a fluoropolymer, heat cured and mixed rigorously with a dissolved silicone using a VibroFix unit until a homogeneous mixture was produced.

\subsection{Sensor design}

The $\mathrm{O}_{2}$ sensitive layer is deposited onto a $600 \mathrm{~nm}$ cut-on dichroic mirror and placed within an optical carrier at an angle of incidence (AOI) of $45^{\circ}$ as shown in Figure 1. To the same carrier, a $420 \mathrm{~nm}$ UV blocking bandpass filter is placed at AOI $0^{\circ}$ which sits directly in front of a $405 \mathrm{~nm}$ LED. Upon excitation of the PtTFPP complex the luminescence signal passes through the dichroic mirror whilst blocking the excitation light and is collected by a photodiode which is connected to a customized printed circuit board (PCB). The PCB also contains temperature and pressure sensors so that measurements can be corrected for changes in the luminescence response due to these environmental variables. All components are fixed compactly into an outer housing containing flow through connections. 


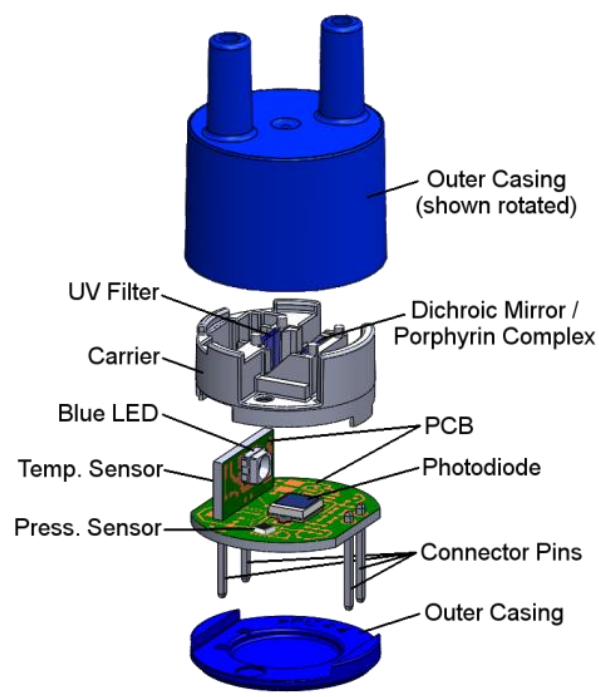

Figure 1: Arrangement of the optical trace $\mathrm{O}_{2}$ sensor.

\subsection{Spectroscopic characterisation}

At Glasgow Caledonian University (GCU) UV-Visible absorption spectra were collected using a Perkin Elmer Lamda 2 dual beam UV-Visible spectrophotometer. Luminescence excitation and emission spectra were collected using a HORIBA Jobin Yvon Ltd FluoroMax-3 spectrophotometer and/or a Hamamatsu C10082CA mini-spectrometer connected to a Thorlabs M45LO2 multimode $400 \mu \mathrm{m}$ fibre patch cable. Luminescence lifetime (decay time) measurements were performed on a HORIBA Jobin Yvon 5000U lifetime instrument using either Multi-channel scaling (MCS) and/or Time correlated single photon counting (TCSPC) mode depending on $\mathrm{O}_{2}$ concentration. In MCS mode a $400 \mathrm{~nm}$ SpectraLED was used as the excitation source and in TCSPC a $440 \mathrm{~nm}$ NanoLED was used.

$\mathrm{O}_{2}$ and oxygen free nitrogen (OFN) gases were purchased from BOC gases and blended to the desired $\mathrm{O}_{2}$ concentration using flow meters. In ambient $\mathrm{O}_{2}$ a factory calibrated SST LuminOx 0-25\% $\mathrm{O}_{2}$ sensor was used as a reference.

\subsection{Sensor characterisation and calibration}

At SST, the sensors were characterized using the experimental arrangement shown in Figure 2. $\mathrm{N}_{2}$ was purchased from BOC gases UK and specialty blended 1300 ppm $\mathrm{O}_{2}$ and $45 \% \mathrm{O}_{2}$ from Air Products UK. An Environics Series 2020 computerized gas blender was used to provide the specific ppm level required which passed to a Cambridge Sensotec Rapidox $2100 \mathrm{O}_{2}$ analyser which was used as a reference. The gas passed to an intercooler within a Heraeus VOTSCH HC 7020 temperature chamber to allow the temperature of the gas to equilibrate before reaching the calibration box. Within the calibration box thermocouples were placed to record the temperature of the gas as well as the box temperature. In addition, the barometric pressure inside the box was recorded using a Cuthbertson Laird DPI142 digital pressure meter. 


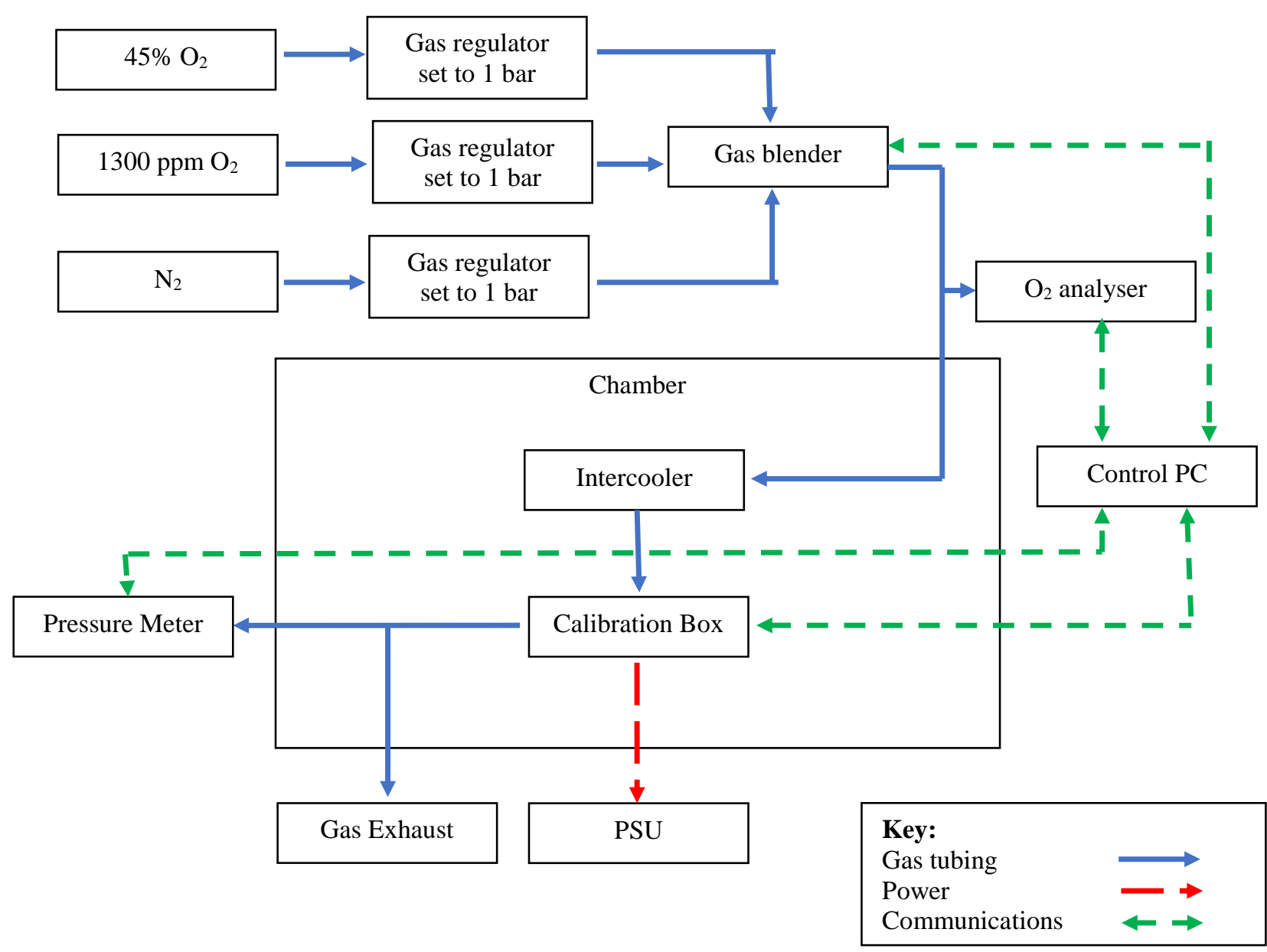

Figure 2: Schematic experimental arrangement for sensor characterisation and calibration.

\section{RESULTS AND DISCUSSION}

\subsection{Sensor characterisation}

Figure 3 shows the absorbance and luminescence emission spectra of PtTFPP including the spectrum of the $405 \mathrm{~nm}$ LED and transmission scans of the optical components. PtTFPP has an intensely absorbing Soret-band at $390 \mathrm{~nm}$ corresponding to an $\mathrm{S}_{0} \rightarrow \mathrm{S}_{2}$ transition and weaker absorbing Q-bands at $504 \mathrm{~nm}$ and $538 \mathrm{~nm}$ corresponding to $\mathrm{S}_{0} \rightarrow \mathrm{S}_{1}$ transitions in the visible spectrum. ${ }^{6}$ PtTFPP within the sensing formulation in this work has a luminescence peak maximum at $645 \mathrm{~nm}$.

There is a reasonable overlap between the Soret-band of PtTFPP and the narrow band of the 405 nm LED providing efficient illumination. Due to the large Stokes shift (difference between absorbance and luminescence peak wavelength) of $240 \mathrm{~nm}$ the signals can be easily distinguished and separated using the optical components shown. The bandwidth of the $405 \mathrm{~nm}$ LED is so narrow that the $420 \mathrm{~nm}$ bandpass filter allows all of the LED light to pass through whilst blocking harmful UV rays $(<350 \mathrm{~nm})$ and any visible light $>480 \mathrm{~nm}$. Additionally, the $600 \mathrm{~nm}$ dichroic mirror blocks light with a wavelength of less than $550 \mathrm{~nm}$, which is critical for avoiding light bleed, but importantly has maximum transmittance at $645 \mathrm{~nm}$ maximizing the amount of luminescence being collected by the photodiode.

To demonstrate the high sensitivity of the sensor, the sensor was exposed to ambient $\mathrm{O}_{2}\left(200\right.$ mbar ppO $\left.\mathrm{P}_{2}\right)$ as shown in Figure 4. In the absence of $\mathrm{O}_{2}\left(I_{0}\right)$ PtTFPP shows an intense luminescence but by $50 \mathrm{mbar}^{\mathrm{ppO}} \mathrm{O}_{2}$ the luminescence 
intensity drops by $\sim 90 \%$ of the original signal. By 200 mbar $\mathrm{ppO}_{2}$ the luminescence intensity of PtTFPP is almost completely quenched. When plotting a Stern-Volmer plot (SVP) using Equation $1, K_{S V}=0.1593 \pm 0.0028 \mathrm{mbar}^{-1}\left(\mathrm{R}^{2}=\right.$ 0.9991 ) with $I_{0} / I=31.74$, when $\mathrm{O}_{2}$ was in the range of 0-200 mbar $\mathrm{ppO}_{2}$.

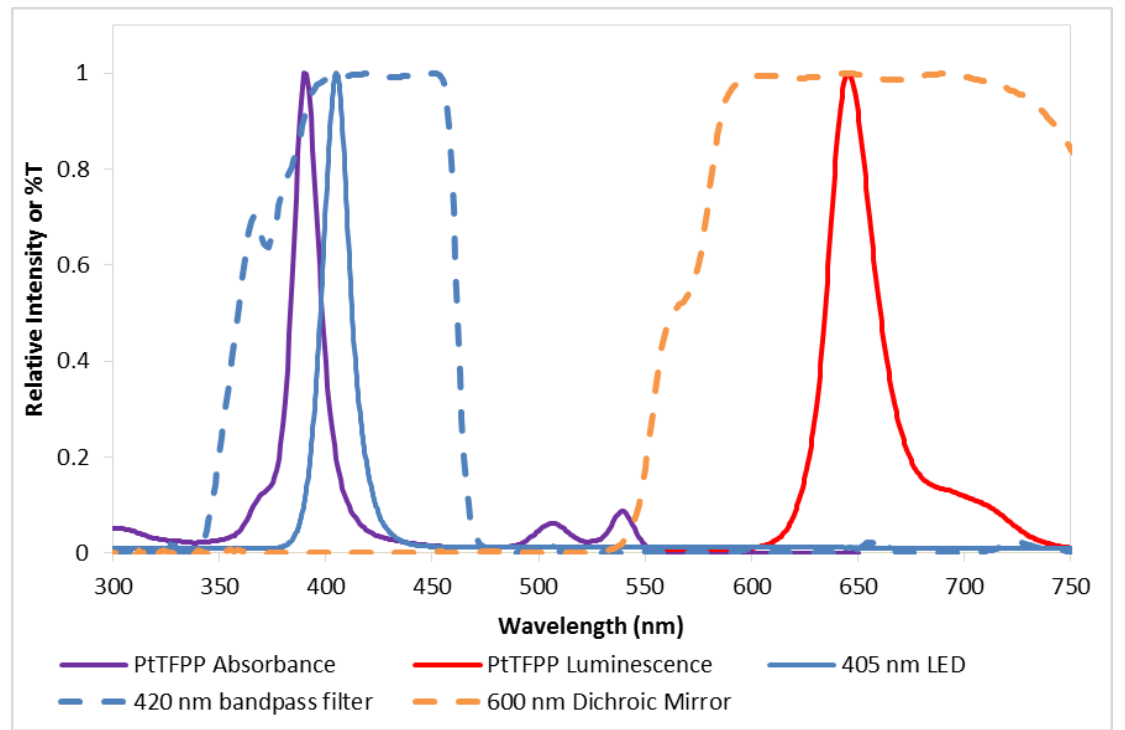

Figure 3: Normalised absorbance and luminescence emission spectra of PtTFPP including the spectrum of the $405 \mathrm{~nm}$ LED and transmission $(\% \mathrm{~T})$ scans of the optical components.

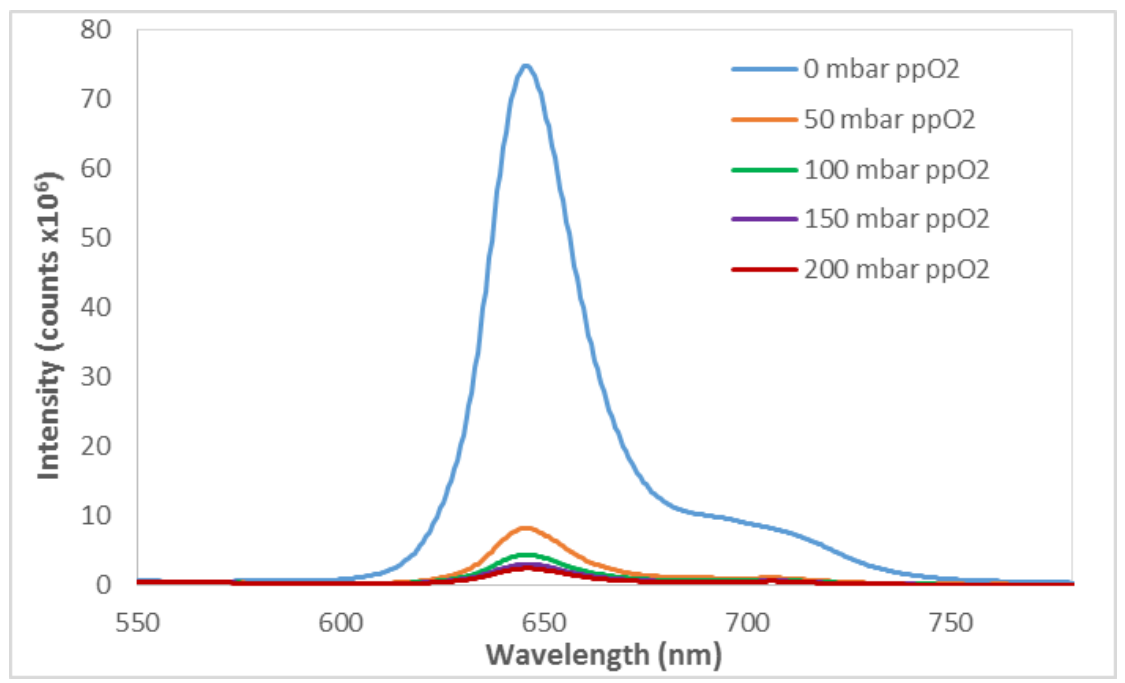

Figure 4: Luminescence emission spectra of the PtTFPP layer to changes in $\mathrm{ppO}_{2}, \lambda_{\mathrm{ex}}=405 \mathrm{~nm}$.

An important aspect of a sensor is its response time to changes in $\mathrm{O}_{2}$, with most manufacturers specifying the T90 response time. In this case, this is the time taken in the increase or decrease in the luminescence decay time $(\tau)$ to $90 \%$ of its original value as shown in Figure 5. The average T90 response time $\left(\mathrm{N}_{2} \rightarrow\right.$ Air) of the sensor is $13.4 \pm 0.5$ seconds with an average T90 recovery time (Air $\rightarrow \mathrm{N}_{2}$ ) of $23.1 \pm 0.7$ seconds. The recovery time of a sensor is generally slower than the response as removing $\mathrm{O}_{2}$ from an environment is more difficult than introducing it.

Like the luminescence intensity results presented in Figure 4, exposure to air (ambient $\left.\mathrm{O}_{2}\right)$ causes $\tau$ to be almost completely quenched. Critically, $\tau$ recovers to the same value demonstrating the repeatability and reversibility of the sensor when switching between $\mathrm{N}_{2}$ and air. This is an advantage over electrochemical-based ppm sensors as they start to 
deplete with time when exposed to ambient $\mathrm{O}_{2}$ i.e. the electrolyte within the electrochemical cell is consumed by $\mathrm{O}_{2}$, the equivalent of several cycles for ambient $\mathrm{O}_{2}$ thus re-calibration or replacement of the electrochemical cell is required periodically.

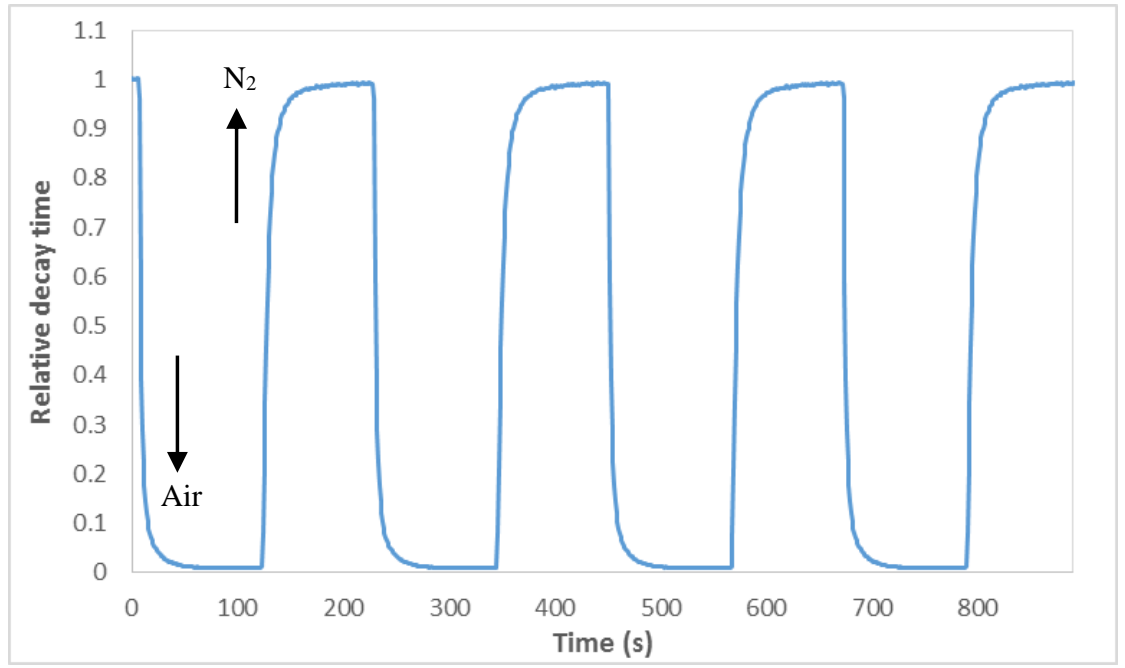

Figure 5: Normalised response and recovery time of the sensor to changes in $\mathrm{ppO}_{2}$.

\subsection{Sensor calibration}

As mentioned above, the successful calibration of a sensor relies heavily on ensuring environmental variables such as temperature are monitored and/or kept constant throughout. In this work, the sensor was calibrated from -28 to $+62{ }^{\circ} \mathrm{C}$ in increments of $15{ }^{\circ} \mathrm{C}$ with a $20{ }^{\circ} \mathrm{C}$ data run being logged at the start and end of the calibration to check for differences as shown in Figure 6. During each temperature, $\mathrm{O}_{2}$ concentrations of 0, 250, 500, 750 and $1000 \mathrm{ppm}$ were introduced with the $\tau$ value being recorded throughout, shown clearer in Figure 7 . Additionally, to demonstrate the robustness of the sensor to higher levels of $\mathrm{O}_{2}$, the sensor was exposed from $5 \%$ to $30 \% \mathrm{O}_{2}$ in increments of 5\% after 0-1000 ppm (Figure 7). Each temperature cycle lasted a total of 16 hours with the first 8 allowing the environmental chamber to stabilize before the $\mathrm{N}_{2}$ gas was switched on. The "blip" observed at the start of the 250 ppm in Figure 7 is caused by a short delay of the gas blender switching the $\mathrm{N}_{2}$ port off and on again to blend with the $1300 \mathrm{ppm} \mathrm{O}_{2}$ cylinder. It can be seen that as $\mathrm{O}_{2}$ concentration increases $\tau$ decreases.

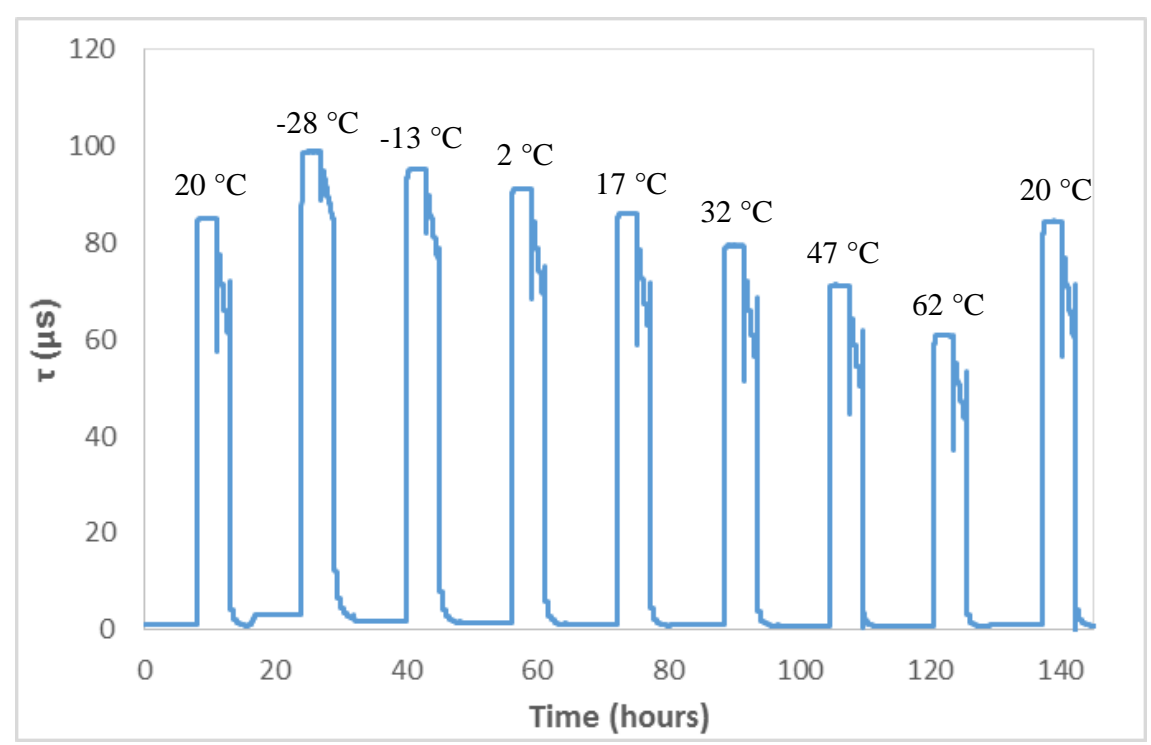

Figure 6: Sensor $\tau$ response to $\mathrm{O}_{2}$ and temperature throughout the full test. 


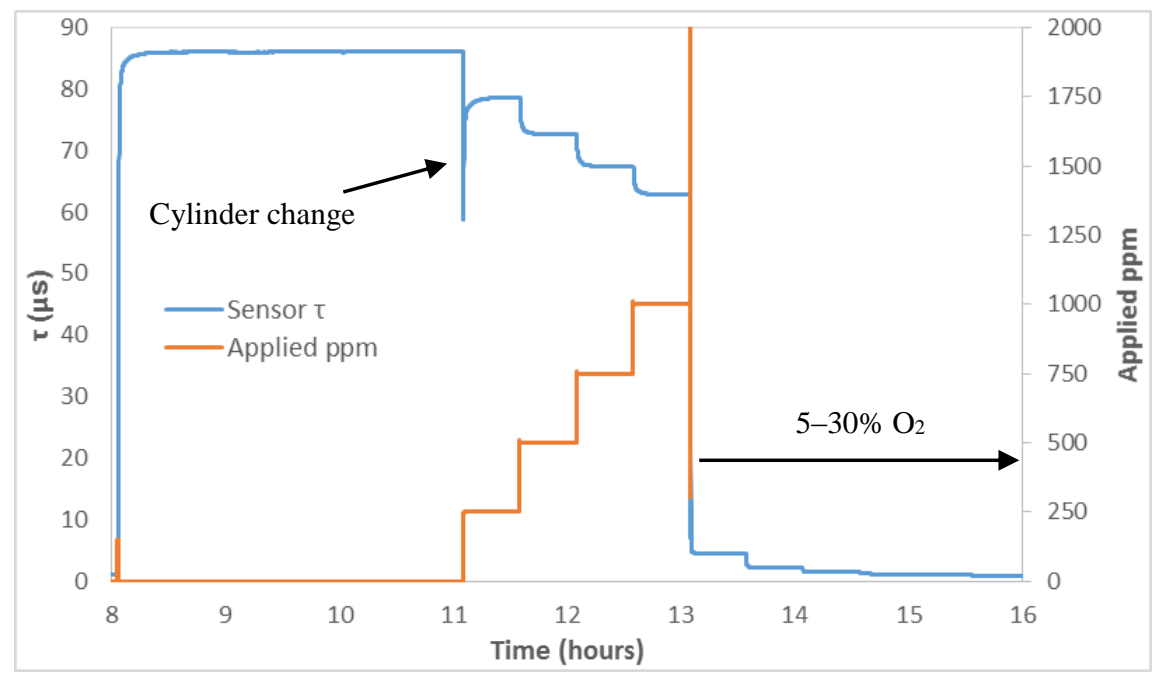

Figure 7: Sensor $\tau$ response to changes in $\mathrm{O}_{2}$ from 0-1000 ppm followed by $5-30 \% \mathrm{O}_{2}$ at $17{ }^{\circ} \mathrm{C}$.

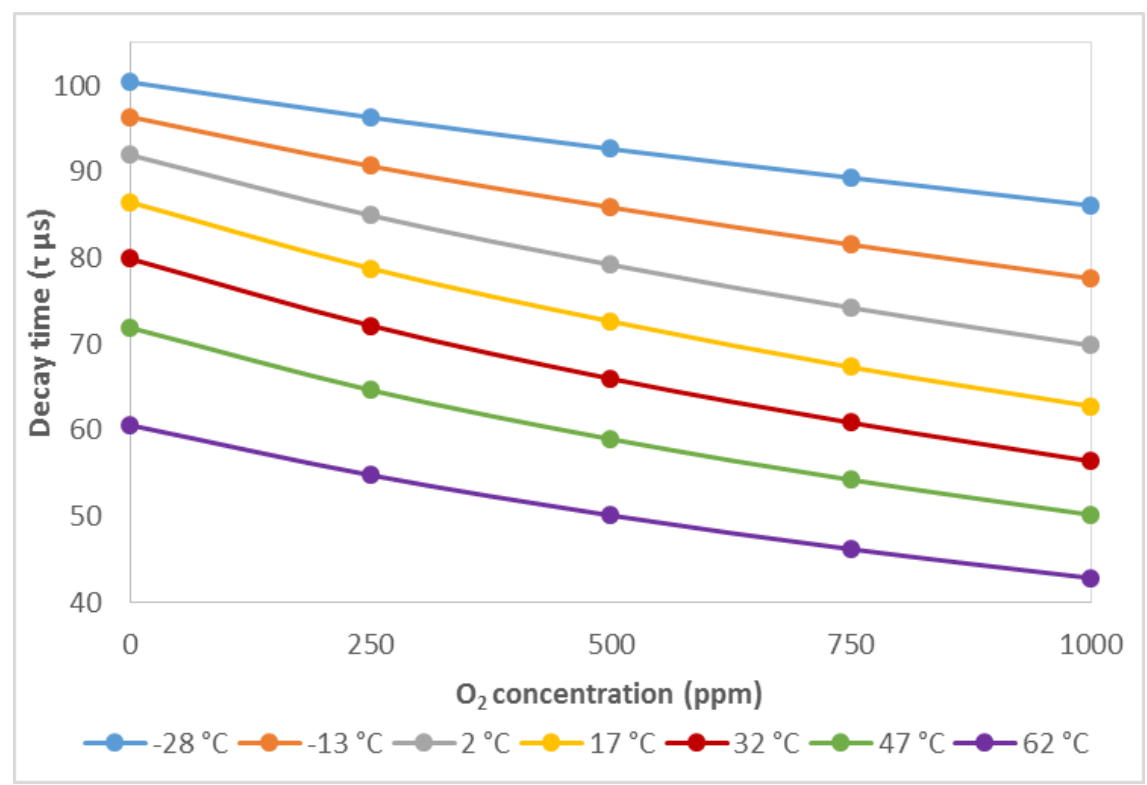

Figure 8: Sensor $\tau$ response to changes with $\mathrm{O}_{2}$ and temperature.

Figure 8 shows the averaged $\tau$ values with $\mathrm{O}_{2}$ ppm over the full temperature range with the associated Stern-Volmer plots (SVPs) presented in Figure 9. Figure 8 highlights the magnitude of the cross-sensitivity of the sensor with temperature with the $\tau$ value showing $\sim 0.4 \mu \mathrm{s} /{ }^{\circ} \mathrm{C}$ thus why taking temperature into account is paramount when calibrating the sensor. The SVPs show a linear correlation between $\tau_{0} / \tau$ and $\mathrm{O}_{2} \mathrm{ppm}$ with temperature over the range with sensitivity increasing with temperature until $47{ }^{\circ} \mathrm{C}$, after which, the sensitivity drops. It is well known that higher temperatures can influence the solubility, diffusion, permeability of gases in polymers as well as the luminescent indicators quantum yield $(\Phi)$ and quenching constants i.e. at higher temperatures $\mathrm{O}_{2}$ tends to diffuse into a polymer faster but the solubility usually decreases as well as the quantum yield of the indicator ${ }^{1}$ which may be the case here. Nevertheless, as long as the temperature is known and implemented into the calibration the output of the sensor will read reliably. Therefore, a calibration table was built containing all the necessary information such as sensor temperature, sensor pressure, barometric pressure of the calibration box, applied $\mathrm{O}_{2}$ from the gas blender and of course $\tau_{0} / \tau$ ratio in order to calculate $\mathrm{ppO}_{2}$ ( $\mu$ bar) and subsequently the actual $\mathrm{O}_{2} \mathrm{ppm}$ value as shown in Figure 10. 


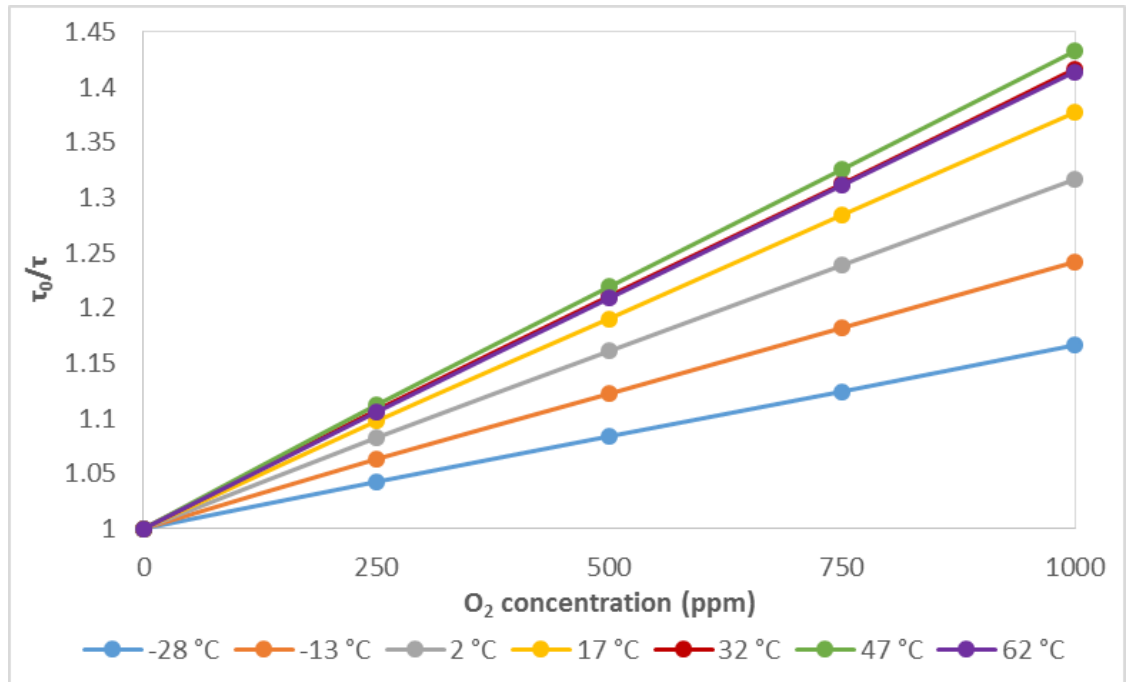

Figure 9: SVPs of the sensor to changes with $\mathrm{O}_{2}$ and temperature.

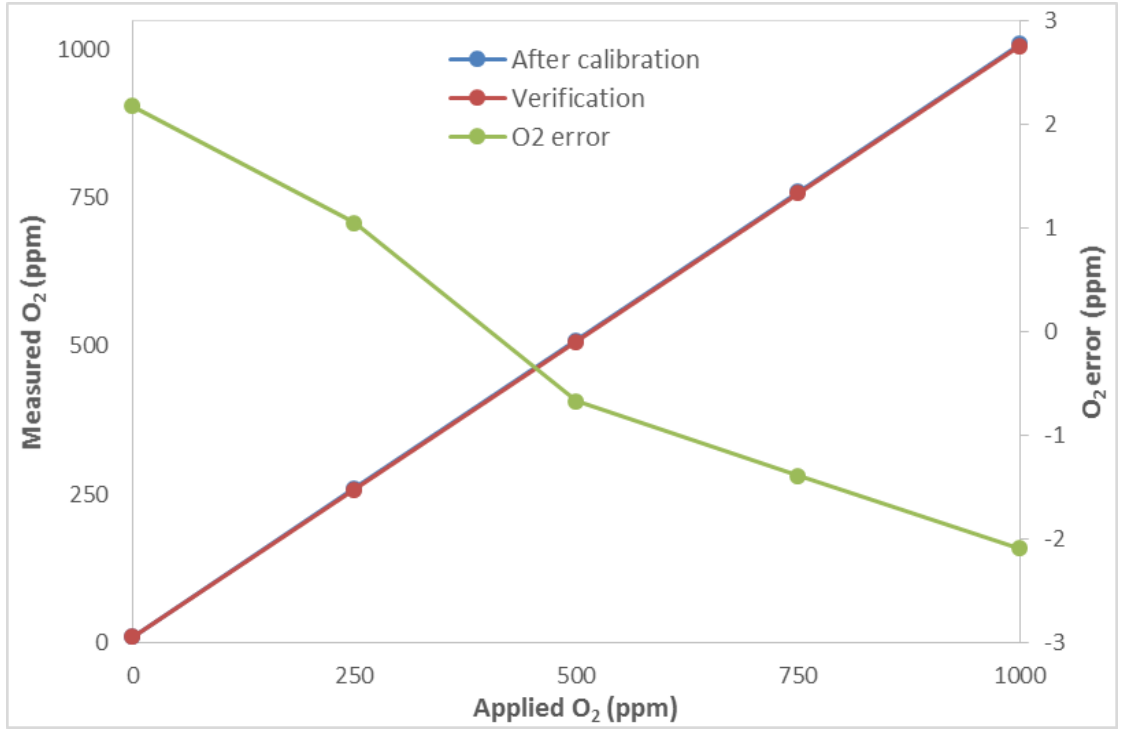

Figure 10: Comparison of the sensor calibration and verification data with associated $\mathrm{O}_{2}$ error.

Figure 10 shows that after calibration of the sensor and running a verification the sensor shows an accuracy of \pm 2.5 ppm over the $0-1000 \mathrm{ppm}$ range, equating to $0.25 \%$ error full scale. The verification involves fixing the temperature to $20{ }^{\circ} \mathrm{C}$ after calibration (see Figure 6), applying the specific $\mathrm{O}_{2}$ concentration of interest and comparing the ppm readings.

In the development of a long-term luminescence-based sensor it is critical that there is little to no photodegradation of the sensing layer. Here, the response of $\tau$ was compared at $20{ }^{\circ} \mathrm{C}$ at the start and end of the calibration run (Figure 6) equating a total of 144 hours whilst the sensors pulsed (100 times per second) throughout with the results presented in Figure 11. 


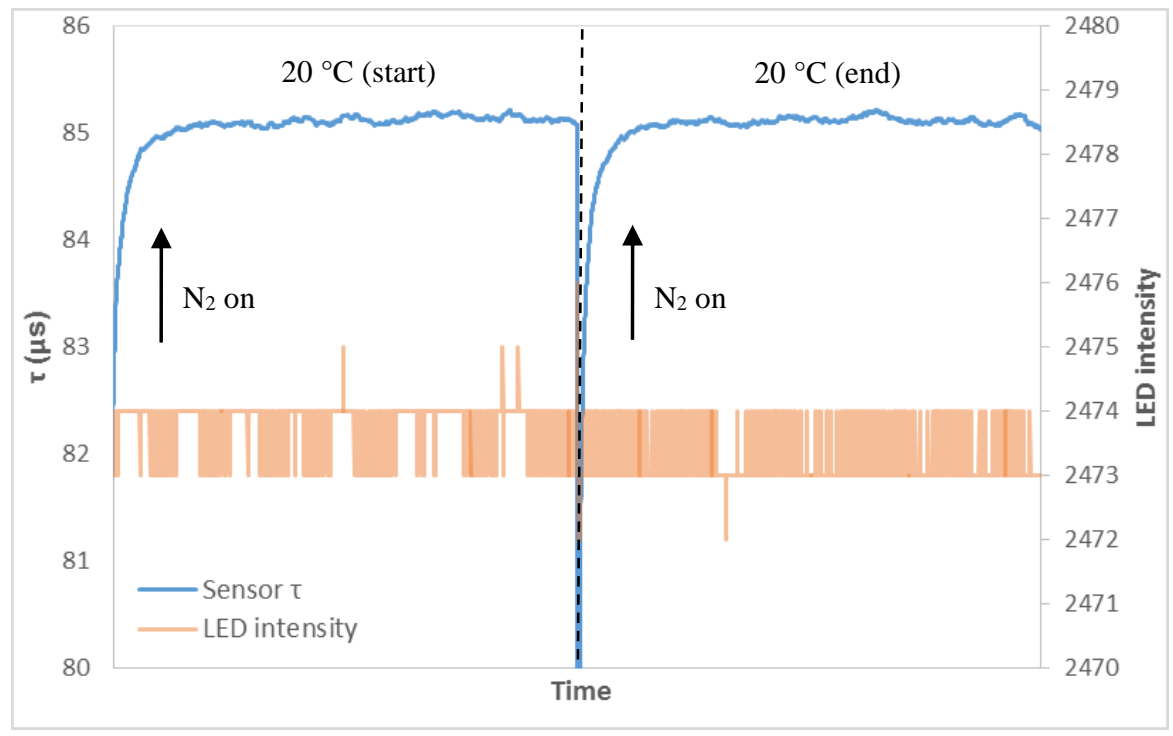

Figure 11: Sensor $\tau$ response and LED intensity at $20^{\circ} \mathrm{C}$ in $\mathrm{N}_{2}$ at the start and end of calibration.

After 144 hours of continuous operation comparing the $\tau$ values showed fluctuations of $\pm 0.02 \mu$ s equating to \pm 0.6 ppm which is within the uncertainty in the measurement of the sensor thus no clear photobleaching was observed. In addition, the electronics within the sensor have the capability of providing an intensity readout from the LED. It can be seen the LED intensity fluctuated by 1 step supporting the claim no photobleaching was observed i.e. if photobleaching was apparent the LED intensity would increase as it would drive harder to obtain the same amplitude of the luminescence intensity.

\section{CONCLUSIONS \& FUTURE WORK}

A novel, compact and miniaturized optical trace $\mathrm{O}_{2}$ ppm sensor has been produced based on the metalloporphyrin complex PtTFPP immobilized within an extremely gas permeable polymer matrix. The sensitivity and selectivity of the oxygen-sensitive layer allows for the detection and quantification of $\mathrm{O}_{2}$ in the $0-1000 \mathrm{ppm}$ range and a relatively wide temperature range of $-30{ }^{\circ} \mathrm{C}$ to $+60{ }^{\circ} \mathrm{C}$. It has been shown the sensor responds quickly and reversibly up to $30 \% \mathrm{O}_{2}$ as well as ppm levels demonstrating the reliability and robustness of the sensor. Additionally, no photodegradation has been observed to date. After calibration, the sensor has an accuracy of $\pm 2.5 \mathrm{ppm}$ which would be adequate for most applications and comes equipped with temperature and pressure compensation making it an attractive alternative to other ppm sensors on the market.

Further work is underway to determine the drift characteristics of the sensor, if any. Steady-state drift will be characterized by monitoring the sensor output continuously within a fixed temperature and $\mathrm{O}_{2}$ environment with time. Thermal drift will be characterized by continuous thermal cycling from $-30{ }^{\circ} \mathrm{C}$ to $+60{ }^{\circ} \mathrm{C}$, bringing the sensors back to a known temperature such as $20^{\circ} \mathrm{C}$ and comparing the applied $\mathrm{O}_{2}$ from $0-1000 \mathrm{ppm}$ against the calibration data of the sensor, ultimately determining its operational lifetime.

\section{REFERENCES}

[1] Wang, X.., Wolfbeis, O. S., "Optical methods for sensing and imaging oxygen: materials, spectroscopies and applications.," Chem. Soc. Rev. 43, 3666-3761 (2014).

[2] Clark, L. C., "Monitor and control of blood and tissue oxygen tensions," Trans. Am. Soc. Artif. Intern. Organs 2 , 41-57 (1956). 
[3] Wu, C. C., Yasukawa, T., Shiku, H.., Matsue, T., "Fabrication of miniature Clark oxygen sensor integrated with microstructure," Sensors Actuators B 110(2), 342-349 (2005).

[4] Lakowicz, J., Principles of Fluorescence Spectroscopy, 3rd ed, Springer, New York (2006).

[5] Wolfbeis, O. S., "Luminescent sensing and imaging of oxygen: Fierce competition to the Clark electrode," BioEssays 37, 921-928 (2015).

[6] Quaranta, M., Borisov, S. M.., Klimant, I., “Indicators for optical oxygen sensors,” Bioanal. Rev. 4, 115-157 (2012).

[7] Bacon, J. R.., Demas, J. N., "Determination of Oxygen Concentrations by Luminescence Quenching of a Polymer- Immobilized Transition-Metal Complex," Am. Chem. Soc. 59(23), 2780-2785 (1987).

[8] Carraway, E. R., Demas, J. N., DeGraff, B. A.., Bacon, J. R., "Photophysics and Photochemistry of Oxygen Sensors Based on Luminescent Transition-Metal Complexes," Anal. Chem. 63, 337-342 (1991).

[9] Wang, X., Wolfbeis, O. S.., Meier, R. J., "Luminescent probes and sensors for temperature.," Chem. Soc. Rev. 42, 7834-7869 (2013).

[10] Liebsch, G., Klimant, I.., Wolfbeis, O. S., "Luminescence Lifetime Temperature Sensing Based on Sol-Gels and Poly(acrylonitrile)s Dyed with Ruthenium Metal-Ligand Complexes," Adv. Mater. 11(15), 1296-1299 (1999).

[11] Baleizao, C., Nagl, S., Schäferling, M., Berberan-Santos, M. N.., Wolfbeis, O. S., "Dual fluorescence sensor for trace oxygen and temperature with unmatched range and sensitivity," Anal. Chem. 80(16), 6449-6457 (2008).

[12] Zelelow, B., Khalil, G. E., Phelan, G., Carlson, B., Gouterman, M., Callis, J. B.., Dalton, L. R., "Dual luminophor pressure sensitive paint II. Lifetime based measurement of pressure and temperature," Sensors Actuators B 96(1-2), 304-314 (2003).

[13] Coyle, L. M.., Gouterman, M., "Correcting lifetime measurements for temperature," Sensors Actuators B Chem. 61, 92-99 (1999).

[14] Kocincova, A. S., Borisov, S. M., Krause, C.., Wolfbeis, O. S., "Fiber-optic microsensors for simultaneous sensing of oxygen and pH, and of oxygen and temperature," Anal. Chem. 79(22), 8486-8493 (2007).

[15] Stich, M. I. J., Schaeferling, M.., Wolfbeis, O. S., "Multicolor fluorescent and permeation-selective microbeads enable simultaneous sensing of pH, oxygen, and temperature," Adv. Mater. 21, 2216-2220 (2009).

[16] Stich, M. I. J., Fischer, L. H.., Wolfbeis, O. S., "Multiple fluorescent chemical sensing and imaging.," Chem. Soc. Rev. 39, 3102-3114 (2010).

[17] Borisov, S. M., Seifner, R.., Klimant, I., “A novel planar optical sensor for simultaneous monitoring of oxygen, carbon dioxide, $\mathrm{pH}$ and temperature,” Anal. Bioanal. Chem. 400, 2463-2474 (2011).

[18] Fuller, Z. J., Bare, W. D., Kneas, K. A., Xu, W. Y., Demas, J. N.., DeGraff, B. A., "Photostability of Luminescent Ruthenium(II) Complexes in Polymers and in Solution,” Anal. Chem. 75(11), 2670-2677 (2003).

[19] Atkinson, R. S., Brimage, D. R. G., Davidson, R. S.., Gray, E., "Use of Tertiary Amino-groups as Substituents to Stabilise Compounds Towards Attack by Singlet Oxygen,” J. Chem. Soc. - Perkin Trans. I 1(9), 960-964 (1973).

[20] Lee, S.-K.., Okura, I., "Photostable Optical Oxygen Sensing Material: Platinum Tetrakis(pentafluorophenyl)porphyrin Immobilized in Polystyrene,” Anal. Commun. 34(6), 185-188 (1997). 